\title{
TEMAS EM DIREITOS HUMANOS DE UMA ORGANIZAÇÃO DA PARAÍBA E 0 MASTER FRAME DE DIREITOS HUMANOS
}

Arlene Martinez Ricoldi

Este artigo apresenta tematizações sobre direitos humanos por uma organização sediada em João Pessoa, na Paraíba, a Fundação Margarida Maria Alves (FMMA). Como outras organizações de defesa de direitos humanos, a FMMA está engajada na defesa de direitos coletivos, assim como na difusão de uma "cultura de direitos humanos", o que faz principalmente por meio de cursos de educação jurídica popular ${ }^{1}$.

$\mathrm{Na}$ pesquisa em questão, fizemos uso do conceito de frames $^{2}$ e master frames para compreender os significados de direitos humanos difundidos no Brasil. O objetivo deste artigo é apresentar como a organização estudada se liga

\footnotetext{
${ }^{1}$ Esses cursos constituem estratégia de mobilização e formação para o ativismo em direitos humanos de diversas organizações, em sua maioria não governamentais. Esse tipo de iniciativa é comumente encontrado em diversos países da América Latina, assim como da Ásia e da África (Rojas, 1988; Schuler e Kadirgamar-Rajasingham, 1992; Cladem, 1991).

${ }^{2}$ Optamos por não traduzir frame, pois não encontramos equivalente satisfatório em português para as múltiplas significações que o termo possui. No entanto, há trabalhos que utilizam o termo "marco" como tradução para frame e "análise de enquadramento" para frame analisys, muito comum em trabalhos na área da comunicação, conhecido também como news framing ou news making (Porto, 2002; Bonelli, 2005)
} 
a esse master frame e quais os temas que escolhe entre os diversos considerados nos direitos humanos. Como poderemos constatar, esses temas são coerentes com a trajetória da organização, que nasce como um Centro de Defesa de Direitos Humanos (CDDH) ligado à Igreja Católica para se tornar uma organização autônoma em meados da década de 1990. Defendemos que, embora sofra influência dos debates internacionais, o master frame de direitos humanos ganha colorações próprias nos diversos países e localidades onde se desenvolve.

O artigo está assim organizado: na primeira parte, apresentamos os conceitos de frame e master frame, para, a seguir, discutirmos a ideia de direitos humanos como master frame no Brasil; na segunda parte, examinaremos a atuação e o frame da FMMA, em especial o desenvolvimento dos cursos de educação jurídica popular. Por fim, a terceira parte trata dos principais temas que privilegia 124 em suas atividades, a partir da análise de boletins informativos que publica regularmente, relacionando-os com o frame da organização.

\section{0 conceito de frame e master frame}

$\mathrm{O}$ artigo clássico que desenvolve o conceito de frame de ação coletiva foi escrito por Snow et al. (1986) visando suprir, segundo sua perspectiva, lacuna na compreensão das motivações da participação e obtenção de apoio aos movimentos sociais. Tomando emprestado o conceito de Goffman (1974), os autores definiram frame como "schemata de interpretação", que permite aos indivíduos

localizar, perceber, identificar e rotular ocorrências no espaço de suas vidas e no mundo em geral. [...] funcionam para organizar experiências e guiar ações, sejam individuais ou coletivas. Assim conceitualizado, segue-se que o alinhamento de frame é uma condição necessária para a 
participação nos movimentos, seja qual for a natureza ou intensidade (Snow et al., 1986, p.464).

Frames são, nessa definição, enquadramentos interpretativos formulados tanto por indivíduos como por organizações ou grupos, isto é, elaborados coletivamente. Os processos de alinhamento de frame descritos são fundamentais para promover a mobilização, o engajamento em atividades dos movimentos, por meio de "conexões" entre os frames individuais e os das organizações dos movimentos. Dito de outra maneira, os frames servem para simplificar e condensar o "mundo lá fora", pontuando e codificando objetos, situações, eventos, experiências e sequências de ações, em um ambiente passado ou presente (Snow; Benford, 1992, p.136-7). Também servem para fazer diagnósticos (identificação do problema) e prognósticos (resolução do problema). Na concepção de Goffman, cada um de nós pode conceber um frame próprio de interpretação da realidade. Porém, nos frames de ação coletiva, são as interpretações constituídas coletivamente o foco da investigação.

Os autores identificaram dois processos de transformação que também são pertinentes ao recrutamento e participação dos movimentos: as de domínio específico ${ }^{3}$ e as de frames interpretativos globais ou master frames.

Snow et al. (1986) apontam os possíveis processos de transformação para frames interpretativos globais, na qual o escopo da mudança é ampliado na medida em que uma nova estrutura primária ganha ascendência sobre outras e vem a funcionar como um master frame. Envolve, essencial-

\footnotetext{
${ }^{3}$ As transformações de domínio específico referem-se a "mudanças autocontidas", mas substanciais na maneira como um domínio particular da vida pode passar a ser visto como problemático ou que necessita correção. Um caso concreto foi o movimento Mothers Against Drunk Driving [Mães Contra a Direção Embriagada]. Nesse caso, o que antes era o infortúnio da perda de um filho foi redefinido como injustiça devido à pouca severidade das penalidades para a direção embriagada.
} 
mente, um tipo de conversão completa representada por uma mudança de "sentido de fundamento último". A transformação de domínio específico, antes agrupada e interpretada, agora é rearranjada e tem novos significados, de acordo com um novo master frame (Snow et al., 1986, p.473). Um caso exemplar citado pelos autores é o movimento pacifista, no qual praticamente todos os domínios da vida, das relações interpessoais aos temas globais, foram reelaborados em termos congruentes com o master frame pacifista. Enquanto os frames correspondem a elaborações de uma só organização ou duas, ou mesmo de um setor de movimentos sociais, os master frames abrangem um número maior de organizações e movimentos.

O processo de elaboração de um master frame pode ser entendido por meio das relações entre este e os ciclos de protesto $^{4}$ (Snow; Benford, 1992). Os autores argumentam a importância desses ciclos para a emergência, sustentação 126 e declínio dos master frames. Por outro lado, consideram cruciais os papéis desempenhados pelos processos de elaboração dos frames (framing) e as redes de significado para a emergência desses ciclos (Snow; Benford, 1992, p.151-2).

A vantagem da utilização de master frame é a consideração dos processos dinâmicos de formulação de significados, aspecto já presente no conceito de frame. A noção de frames implica considerar que os movimentos não são meramente portadores de ideias e significados preexistentes, mas estão ativamente engajados na sua produção e manutenção. Esse trabalho produtivo pode envolver a amplificação e extensão de significados existentes, a transformação de antigos significados e a geração de novos. O conceito de master frame também considera os movimentos funcionando, em parte, como agentes significadores profundamente enredados

\footnotetext{
${ }^{4}$ Ciclos de protesto são caracterizados pela emergência de novas tecnologias de protesto, que se difundem de um ponto de origem para outras áreas e setores do protesto social (Tarrow apud Snow et. al., 1986, p.477).
} 
na mídia, nos governos locais e no Estado, o que tem sido denominado "políticas da significação" (Hall apud Snow; Benford, 1992, p.136). Para os autores, os frames correspondem a elaborações de uma só organização ou duas, ou mesmo de um setor de movimentos sociais, enquanto os master frames abrangem um número maior de organizações.

Uma das críticas a essa abordagem é que os frames de ação coletiva seriam apenas outro nome para ideologia, ou, pelo menos, têm sido utilizados dessa forma por alguns pesquisadores (Oliver; Johnston, 2000), em especial quando utilizada a noção de master frames. Snow e Benford admitem que a noção de ideologia possua relações com os frames e master frames, fornecendo frequentemente elementos para sua elaboração. Porém, acreditam que ideologia tem sido utilizada de maneira mais descritiva do que analítica e de forma estática mais do que dinâmica (Snow; Benford, 1992, p.135). A vantagem da utilização de master frame, nesses casos, seria a consideração dos processos dinâmicos de formulação de significados. Os fatores ideacionais, até então, eram tomados como constantes (não sujeitos a renegociações e disputas em torno de significações) e ubíquos (não sujeitos a contínuas reformulações) (Snow; Benford, 1992, p.135-6). Isso significava também ignorar a extensão à qual os movimentos estariam engajados no "trabalho significador" [meaning work].

Oliver e Johnston (2000), no entanto, acreditam que a noção de ideologia tem sido gradualmente substituída pela de frames/master frames, e de maneira imprópria. Isso se deve, em boa parcela, ao uso pejorativo derivado do sentido de falsa consciência dado pelo pensamento marxista ao conceito de ideologia. A solução proposta por eles é a de manter os dois conceitos, diferenciá-los e adequadamente aplicá-los. Na concepção dos autores, ideologia guarda aspectos mais estáveis no tempo e relação com o pensamento científico e suas regras de validação. Os frames e master fra- 
mes guardariam seu aspecto operativo, buscando elementos na ideologia, assim como em sistemas de crença, nas religiões e questões do cotidiano. Um exemplo adotado pelos autores é o trabalho de Luker (apud Oliver; Johnston, 2000, p.38-9) sobre os movimentos pró e antiaborto nos Estados Unidos. Ambos reformulam seus nomes, para "pró-vida" (antiaborto) e pró-escolha (pró-aborto). Nessa reformulação, adotam o master frame dos direitos civis, porém, de um lado reivindica-se o direito à vida do feto, e, de outro, o direito das mulheres sobre o próprio corpo. Para Oliver e Johnston, nesse caso fica clara a utilidade da distinção entre ideologia e master frames: o mesmo master frame de direitos civis foi igualmente mobilizado por movimentos com ideologias opostas (2000, p.39).

Outra crítica é justamente ao uso "estático" do conceito, que está contido no próprio termo, uma vez que frame também significa "fotograma”, isto é, cada um dos quadros

128 dos filmes realizados em película. Para Steinberg (1998), muitos estudos têm utilizado o conceito com fins meramente descritivos, o que pouco faz avançar o conhecimento sobre os movimentos sociais. Steinberg defende a utilização de perspectiva bakhtiniana dos estudos sobre discurso para acentuar o caráter conflitivo, contextual e dinâmico dos frames. Porém, parece haver aí um limite dado pelo próprio conceito: por mais que se analisem os framing, inevitavelmente a descrição destes "congela" o processo em um dado momento. A defesa do uso desses conceitos feita por Snow e Benford - autores referência dessa abordagem - geralmente ocorre no sentido de afirmar que os estudos de frames de ação coletiva são muito mais sobre os framing, isto é, sobre o trabalho significador, do que sobre o conteúdo dos frames em um dado momento.

A noção de ressonância também se mostra fundamental para a abordagem dos frames. Pode ser compreendida como o grau em que um frame potencialmente pode obter apoio 
ou ser interpretado como efetivo. A análise deste depende de fatores como consistência entre crenças, reivindicações e ações; credibilidade empírica dos frames, ou seja, a capacidade destes serem verificados, o que depende, por sua vez, da credibilidade de seus articuladores e da importância dos alvos da mobilização (Snow; Benford, 2000, p.619-22). Isso porque as conexões possíveis entre os ativistas e os frames dependem de estruturas preexistentes de significação.

$\mathrm{Na}$ perspectiva desse artigo, a consideração de elementos culturais, locais, regionais ou nacionais tem lugar na abordagem, explicando aspectos importantes de como determinados frames obtêm ressonância e outros não.

\section{Direitos Humanos como master frame}

De acordo com os conceitos de frame e master frame expostos acima, defenderemos que os direitos humanos constituíram-se em um master frame, em vigor entre as organizações de defesa de direitos humanos no Brasil. Da mesma forma, esse master frame se difunde, por meio dos organismos e organizações internacionais, ganhando colorações locais ${ }^{5}$.

A noção de direitos humanos como universal vem sendo elaborada desde o final da Segunda Guerra Mundial, tendo como marco inicial a Declaração de $1948^{6}$. Porém, a ideia de universalidade desse rol de direitos não é pacificamente aceita, encontrando impasses e obstáculos de natureza cultural, cuja principal acusação é a sua matriz ocidental e eurocêntrica, o que o tornaria um sistema imposto pelas

\footnotetext{
${ }^{5}$ Não ignoramos que a ideia de um master frame de direitos humanos tem origem nos esforços dos organismos internacionais (notadamente, os da ONU) de generalizar e universalizar essas ideias. Porém, não é possível ignorar como, em contextos nacionais, regionais e/ou locais, elas são reapropriadas e ganham colorações próprias, de acordo com interesses, culturas e contextos particulares. Por isso, trataremos aqui da ideia de um master frame de direitos humanos no Brasil sem, no entanto, desconsiderar suas fontes externas de elaboração.

${ }^{6}$ Reis (2011), a propósito, explora como a tradição latino-americana de direitos humanos elabora essa noção em nível internacional, assim como da própria Declaração de 1948.
} 
nações mais fortes e ricas às demais. Não vai longe o tempo em que os direitos humanos foram identificados como parte integrante de uma política da Guerra Fria (Santos, 1997), e, portanto, vistos com desconfiança entre os que tinham um posicionamento político mais à esquerda. O fato é que a defesa dos direitos humanos tem se tornado uma plataforma quase incontestável no embate político, mesmo que forças conservadoras ${ }^{7}$ tentem lhe pespegar a denominação de "defesa de bandidos" . No entanto, apesar de resistências por se tratar de uma elaboração claramente ocidental, originada nos EUA e Europa, um master frame de direitos humanos vem sendo difundido e utilizado por diversos segmentos dos movimentos sociais, que vêm se alinhando às suas orientações principais.

No caso do master frame de direitos humanos no Brasil, pode-se encontrar, pelo menos, dois ciclos principais que lhe dão origem. O primeiro é aquele que ocorre durante a 130 organização da resistência ao regime autoritário no Brasil, na qual a defesa é a dos direitos civis mais básicos, seja do direito à vida, à liberdade de expressão e ao de ir e vir, em face das prisões políticas e desaparecimentos praticados nessa época. Posteriormente, já no período democrático, temos a intensa mobilização de organizações não governamentais desde meados dos anos de 1980, com grandes movimentos como o Diretas Já e o de participação na Constituinte. Essas

\footnotetext{
${ }^{7}$ Apesar de haver um senso comum que circula tais ideias e alguns representantes que se arrogam seus defensores, é difícil defender a existência de um contraframe elaborado por movimentos rivais, como fica evidente em outros casos, como nas disputas entre sem-terras e ruralistas, ou entre feministas e Igreja Católica (sobre o direito ao aborto).

${ }^{8} \mathrm{Na}$ Paraíba, como em todo o Brasil, a proteção dos direitos humanos esteve associada à "defesa de bandidos", noção que advinha do tratamento distorcido dado à defesa que se fazia daqueles que, ao lutar contra o regime militar na clandestinidade, acabavam presos, torturados e mortos. Como se sabe, esse argumento foi posteriormente estendido para defender o fim da tortura como método de investigação policial. Assim, definir a proteção dos direitos humanos como uma defesa dos direitos de diversos segmentos, com ênfase nos segmentos mais desfavorecidos, não deixa de ser uma forma de combater seus detratores.
} 
lutas acabam por serem codificadas sob a égide dos direitos humanos quando da mobilização para as Conferências Internacionais de Direitos Humanos ${ }^{9}$ da década de 1990 da ONU, constituindo o segundo ciclo. Esse processo intensificou o intercâmbio e a mobilização internacional das organizações não governamentais já iniciados na década anterior. A participação nessas conferências unifica plataformas e provoca alianças internacionais em torno de questões de direitos humanos. Tendo herdado um certo segmento de ativistas da resistência ao regime militar, a defesa de direitos humanos também se amplia com a explosão do número de ONGs ocorrida na primeira metade da década de 1990, fenômeno este resultado da redução do Estado na área social e da consequente delegação da execução de políticas sociais para organizações não governamentais.

Como dissemos, a movimentação internacional acontece logo após a conclusão do processo constituinte, em 1988. Novos direitos, novas leis e necessidade de regulamentação da nova Constituição dão impulso a movimentos por direitos - inclusive à organização de operadores públicos do direito $-{ }^{10}$, que talvez pudéssemos chamar de frame de justiça ${ }^{11}$.

No caso das organizações em defesa de direitos humanos brasileiras, podemos ver uma forte influência da Igre-

\footnotetext{
${ }^{9}$ As conferências mundiais são uma estratégia da ONU e suas agências desde a fundação desta, mas as diversas conferências da década de 1990 ficaram conhecidas pela organização paralela de entidades não governamentais dos diversos países participantes. Os seus documentos finais são amplamente invocados como parâmetros em direitos humanos por governos e movimentos sociais. Entre essas conferências, temos a Eco 92 (Rio de Janeiro), Direitos Humanos (Viena, 1993), População e Desenvolvimento (1994), Mulher (1995), entre outras. Mais tarde, já no início da década seguinte, ocorreu a Conferência Mundial Contra o Racismo (Durban, 2001).

${ }^{10}$ Podemos citar como exemplo disso a Associação de Juízes pela Democracia (AJD) e o Movimento do Ministério Público Democrático (MPD), ambos criados em 1991.

${ }^{11}$ Essa ideia me foi sugerida por Angela Alonso, por ocasião de sua participação na minha banca de doutorado.
} 
ja Católica progressista. Se tomarmos como exemplo o Movimento Nacional de Direitos Humanos (MNDH), que congrega diversas organizações do gênero, veremos entre seus financiadores grandes agências internacionais de orientação religiosa (sejam católicas, cristãs ou ecumênicas), que influenciam sobremaneira esse master frame ${ }^{12}$ no Brasil. Entre as agências, mesmo as de orientação leiga, podemos encontrar, de maneira geral, a defesa dos direitos dos "pobres", também entendidos como "povo" ou "excluídos", e a consequente defesa e estímulo à organização de grupos e segmentos "populares". Essa perspectiva é muito próxima daquela das correntes progressistas da Igreja Católica, influenciadas pela Teologia da Libertação, que interpreta a pobreza como injusta, resultado das ações humanas e não um desígnio divino. Os segmentos progressistas dessa igreja foram responsáveis pela criação dos CDDHs, no período da ditadura militar - muitos até 132 hoje ativos -, contando com advogados que defendiam e prestavam consultoria jurídica a movimentos e grupos em casos de violação de direitos.

É interessante observar que a escolha das agências financiadoras não pode ser atribuída mecanicamente à disponibilidade de financiamento ou possibilidade de acesso a recursos, mas em especial à afinidade entre estas e as linhas de atuação de ONGs. As escolhas e os projetos das ONGs de defesa dos direitos humanos são influenciados por essa origem dentro dos organismos da Igreja Católica progressista e pelo apoio, direto ou indireto, que recebem destes ainda hoje. Nesse sentido, pode-se afirmar que há um alinhamento de frame entre as agências financiadoras e suas organizações, como o exemplo da FMMA pode corroborar.

\footnotetext{
${ }^{12}$ Para uma análise pormenorizada das missões e valores de agência financiadoras do MNDH e da FMMA, ver Ricoldi (2011).
} 


\section{A Fundação Margarida Maria Alves e os Juristas Populares}

A FMMA é uma organização não governamental que foi instituída juridicamente como fundação em 1994, quando a arquidiocese da Paraíba resolveu conceder autonomia ao seu antigo CDDH. Este fora criado pela arquidiocese em 1976 para dar assessoria jurídica aos camponeses em conflitos de terra (Mitidiero, 2008, p.303). Era um dos organismos da arquidiocese criados (entre Comunidades Eclesiais de Base e Pastorais) durante o episcopado de Dom José Maria Pires (conhecido também como "Dom Pelé"), religioso de cepa progressista. Pires permaneceu longo período à frente da arquidiocese da Paraíba (1965-1995) e sua gestão progressista ainda teve mais uma breve sobrevida com seu sucessor, Marcelo Carvalheira (1995-2004). Porém, com a iminente mudança de orientação da arquidiocese ${ }^{13}$ diante da aproximação do fim do episcopado de Carvalheira, o CDDH é transformado em fundação ${ }^{14}$.

O passado de serviço pastoral da FMMA, no entanto, deixou vestígios; o seu conselho curador é composto por um representante do arcebispo; um representante do colégio de consultores da arquidiocese da Paraíba; três representantes das Pastorais da arquidiocese; cinco representantes de entidades civis comprometidas com a defesa de direitos humanos e três representantes da equipe técnica-administrativa da fundação. Esses últimos, no entanto, têm direito à voz, mas não a voto. Isso não significa, na prática, que a arquidiocese dirija e controle de perto todas as atividades da FMMA. O conselho curador reúne-se de três em três meses, com um quórum flutuante. Além do mais, discutem

\footnotetext{
${ }^{13}$ A partir de 2004, assume o arcebispo Dom Aldo Pagotto, de linha conservadora, contrário às ações progressistas do episcopado anterior.

${ }^{14}$ A ideia de criar uma fundação (e não uma associação, ou organização não governamental) se deu em razão da possibilidade dessa configuração jurídica poder mover ações civis públicas, em favor de direitos coletivos.
} 
questões de natureza mais ampla, além de superintender e supervisionar o trabalho cotidiano. Também acumulam outras funções importantes, embora de mais rara frequência, como a de assinar convênios e aprovar planos de ação anuais (FMMA, 2008).

O nome da FMMA foi homenagem à presidenta do Sindicato dos Trabalhadores Rurais da cidade de Alagoa Grande, na Paraíba, assassinada em 1983, que remete às suas origens de defesa dos trabalhadores rurais. Porém, a atuação da fundação desde sua criação é de base urbana, atendendo "comunidades" e intermediando suas demandas nos espaços de formulação de políticas públicas, com o Estado ou o Poder Judiciário, para reivindicar direitos.

A Igreja Católica, sentindo-se ameaçada pelos efeitos da sociedade moderna, vistos como negativos, tais como a "racionalidade das instituições e o desapego às relações de tipo primário, especialmente as referidas à família e à religião", pre134 ocupa-se em preservar "comunidades" (Doimo, 1995, p.91). Ocupando uma lacuna proporcionada pela ausência do Estado nessas "comunidades", geralmente definidas como localidades pobres e desprovidas de infraestrutura, a Igreja procura preencher esse espaço tornando-se o liame entre família e vizinhança, ao mesmo tempo que dá voz às suas demandas, proporcionando condições para que estas sejam elaboradas.

Atuando nessa mesma perspectiva, no seu início, a FMMA funciona, sobretudo, como um "balcão de direitos”, com muitos advogados e até um defensor público à disposição para atender a população. Porém, o trabalho interminável e o atendimento de inúmeros casos de pouca complexidade, às vezes de resolução administrativa (como requisição de aposentadoria ou queixas de consumo) fez a FMMA optar por um trabalho educativo ("Socializando o Direito”), constituído de palestras para a população (em especial, comunidades pobres). A parte advocatícia irá se restringir a casos de direitos coletivos. Assim, reformula-se 
o projeto inicial, e com a assessoria de duas organizações que já trabalhavam há alguns anos com educação jurídica popular, Associação de Advogados de Trabalhadores Rurais no Estado da Bahia (AATR) ${ }^{15}$ e a Themis ${ }^{16}$, a FMMA cria o curso de juristas populares em 1999.

Com o passar dos anos, o curso cada vez mais incorpora novas técnicas e metodologias, buscando facilitar a apreensão dos conteúdos tratados, entre eles dinâmicas de grupo, peças teatrais e apostilas. Em 2005, a FMMA decide não aceitar mais inscrições de pessoas com curso superior concluído (graduandos eram permitidos, porém, a prioridade era dada a quem tivesse menos escolaridade), numa mudança que pretende dar um caráter mais "popular" ao curso.

O curso de juristas, um dos principais projetos da FMMA, teve apoio de agências internacionais católicas, todas centradas no combate à pobreza. No seu primeiro ano, o curso de juristas populares teve apoio financeiro da fundação alemã Cordaid ${ }^{17}$. Em 2004, tem projeto institucional trienal apoiado tanto pela Cordaid como pela Catholic Agency For Overseas Development (Cafod) ${ }^{18}$. Na sua décima edição, em 2009, o curso ofereceu 30 vagas. A seleção é baseada na participação em movimentos sociais "desde que o grupo esteja organizado, tenha reuniões regulares e uma coordenação constituída, mas não é necessário ter CNPJ" (FMMA, 2006). É preciso apresentar pelo menos dois candi-

\footnotetext{
${ }^{15}$ A AATR empreende cursos de formação em educação jurídica popular desde o início da década de 1990, também com experiência em conflitos de terra e mais ligada às questões agrárias. O curso "Juristas leigos" compreende a formação de homens e mulheres.

${ }^{16}$ A Themis é uma organização não governamental feminista, sediada em Porto Alegre, que realiza capacitação legal a mulheres (o curso "Promotoras legais populares") desde meados da década de 1990, num formato disseminado via Comitê Latino-Americano de Defesa da Mulher (Cladem), uma organização feminista internacional, voltada para a educação em direitos para mulheres.

${ }^{17}$ A Cordaid é uma organização que resulta da fusão, em 1999, de três organizações católicas holandesas, Memisa, Mensen in Nood e Bilance, todas fundadas no início do século XX.

${ }^{18}$ A Cafod é a agência católica oficial da Inglaterra e País de Gales, fundada em 1960.
} 
datos às vagas por organização. As aulas são ministradas aos fins de semana, uma ou duas vezes ao mês. O perfil do jurista popular compreende estar apto, após a formação, "a fazer os principais encaminhamentos no meio jurídico, mesmo não podendo atuar como advogado, além de orientar os cidadãos aos órgãos competentes para resolverem seus problemas judiciais e extrajudiciais" (FMMA, 2006). A FMMA estima que, nestes mais de dez anos de curso, tenham sido formados cerca de 180 juristas populares.

Durante o terceiro curso de juristas leigos (realizado em 2002), surge a ideia de uma rede de juristas, a partir de uma demanda dos cursistas dessa turma, que indagavam sobre os outros que haviam se formado em anos anteriores, o que eles faziam, e se não atuavam coletivamente. Em resposta a essa demanda, a FMMA passa a promover encontros entre os cursistas daquele ano e dos anteriores, e a rede surge desse processo, entendido como mais uma forma de 136 atuação e fortalecimento do trabalho.

Atualmente, a Rede de Juristas Populares possui quatro núcleos em três cidades da grande João Pessoa: um na capital, dois em Santa Rita (Tibiri e Forte Velho) e um em Bayeux. A Rede conta com financiamento da Misereor ${ }^{19}$, acordado inicialmente por três anos (20072009) e renovado até o final de 2012 (FMMA, 2011). Isso significou ter um técnico da FMMA designado somente para acompanhar suas atividades, organizando, facilitando a comunicação, documentando as reuniões, trazendo informações e sugerindo ações e estratégias além de dar apoio para as atividades que os núcleos desejam realizar. As reuniões e atividades, porém, eram planejadas e realizadas pelas reuniões mensais nos núcleos de juristas, os quais participam sem qualquer remuneração.

\footnotetext{
${ }^{19}$ A Misereor é uma agência da Igreja Católica alemã, fundada em 1958. Seu nome tem origem na frase latina: Misereor super turbam (Estou com pena do povo).
} 


\section{O frame de direitos humanos da Fundação Margarida Alves} Para a delimitação do frame da FMMA utilizaremos como fonte, principalmente, um boletim informativo que a organização publica desde 2002, que nasce com o nome de Intergrupos, passando a se chamar Falando DHireito em 2004. O Intergrupos durou quatro edições e foi realizado pela FMMA em parceria com diversos grupos ${ }^{20}$, desde associações comunitárias até fóruns para discutir questões mais amplas. Fica claro, no entanto, que a responsabilidade maior pelo informativo tanto em termos editoriais, como de recursos humanos e financeiros para realizá-lo é da FMMA. Os grupos associados, em geral, incluem aqueles que são "acompanhados" pela FMMA, quer dizer, os grupos aos quais a FMMA prestava assessoria, em especial porque tem representantes entre os juristas que fizeram ou faziam o curso à época.

O Intergrupos se ocupou de noticiar a participação da FMMA em diversos fóruns, como o Fórum de Reforma Urbana (Ferurb), o Fórum de Controle Externo do Judiciário (Focoej) e a Articulação Estadual de Políticas Públicas, todos eles espaços da sociedade civil nos quais se discutiam políticas para os diversos temas tratados. Em particular, esses fóruns faziam denúncias e articulavam pressões sobre determinados problemas. Esse primeiro momento do informativo da FMMA reflete a nova orientação da organização, atuando como uma organização autônoma leiga. Assim, a FMMA passa a prestar assessoria a grupos e a participar de fóruns, optando por concentrar-se em casos coletivos. A partir de então, ela entende que os casos individuais poderiam ser em grande parte resolvidos com a capacitação jurí-

\footnotetext{
${ }^{20}$ Comunidade Operária do Bairro das Indústrias, Associação Comunitária do Jardim da Mônica, Movimento de Promoção da Mulher, Comitê de Cidadania, Grupo Flor Mulher, Fórum de Reforma Urbana, Articulação Estadual de Políticas Públicas, Centro de Direitos Humanos Dom Oscar Romero, Movimento Cidadania e Segurança.
} 
dica de lideranças já envolvidas com associações ou grupos mais ou menos organizados.

A missão da FMMA é definida em seu estatuto como "fortalecer e difundir uma cultura de respeito aos direitos humanos, na perspectiva dos movimentos populares e da justiça social” (FMMA, 2008a, p.1). O documento ainda destaca entre os movimentos e grupos que procura assessorar, os de defesa da mulher, da criança, dos adolescentes e do meio ambiente. As maneiras como a FMMA se compromete a perseguir seus objetivos incluem educação e capacitação, fortalecimento da participação e organização, denúncias de violação, uso de instrumentos jurídicos (FMMA, 2008a, p.1-2).

O tema dos direitos humanos é tratado de forma ampla e abrangente. No segundo número do boletim Intergrupos, o editorial assinado pela técnica da FMMA Cândida Magalhães, que critica a política de privatizações e o "desmonte 138 do Estado", apontado como "descompromisso do Estado com as Políticas Públicas", procura distinguir os direitos humanos de "defesa de criminosos".

Direitos humanos não é isso [defesa de criminosos]. direitos humanos tratam de um conjunto de direitos, como: trabalho, saúde, educação, moradia, alimentação, justiça social, igualdade de oportunidades especialmente, o combate às desigualdades de gênero, classe social, raça, etnia e geração.

Somente projetos coletivos de organização e lutas podem romper com a brutalidade da vida de injustiças sociais presentes na cena brasileira.

A atuação de sujeitos plurais envolve necessidades e aspirações de mulheres e homens, que retomam sonhos, esperanças e alimentam a luta por uma sociedade mais justa e coletivamente trabalham na construção da democracia e conquista da cidadania plena e ativa (Magalhães, 2002). 
Essa perspectiva de defesa de direitos humanos, portanto, também tem alvos preferenciais: determinados segmentos que estariam em desvantagem em relação aos sistemas econômico e político.

Outro artigo, escrito por Mário Ypiranga Neto ${ }^{21}$ e reproduzido no boletim da FMMA (já havia sido publicado na página da internet Portal Amazônia), enfatiza essa forma de entendimento da defesa dos direitos humanos no frame interpretativo da FMMA:

Engana-se quem pensa que os direitos humanos regem as relações entre iguais. O Direito dos direitos humanos opera na proteção dos mais desvalidos, na defesa dos ostensivamente mais fracos, dos excluídos desses direitos mais elementares, dos famintos e dos iletrados do Brasil. A miséria e a fome são questões humanitárias tão importantes quanto o combate à tortura policial e negar os primeiros parece-me tão grave quanto desconsiderar o último [...] (Ypiranga Neto, 2009).

Defender direitos humanos significa atuar política e juridicamente em face do domínio do aparato do Estado pelas elites econômicas. Não se trata, no entanto, de abandonar as vias institucionais, mas de tomá-las e democratizá-las.

A noção de direitos humanos contida no frame da FMMA, porém, não corresponde exatamente às atividades que abraça. Sempre se definindo como "entidade de direitos humanos", a sua atuação esteve mais ligada à defesa da reforma urbana, direito à cidade, questões de usucapião, sempre no campo dos direitos coletivos e ligados às necessidades dos grupos assessorados, como veremos a seguir.

\footnotetext{
${ }^{21}$ Promotor de justiça e escritor, ele não pertence ao quadro da FMMA, mas a reprodução do artigo reflete, indubitavelmente, a concordância com seu conteúdo.
} 


\section{Temas, injustiças e estratégias}

Na análise das notícias sobre a atuação da FMMA, pudemos distinguir quatro grandes temas: controle social; reforma urbana e direito à moradia e à terra; meio ambiente; gênero/mulher.

Essa análise contou com quatro níveis internos de abrangência: 1. tratou da elaboração de políticas e leis, assim como a intervenção direta em políticas, que inclui a participação em espaços de consulta e deliberação coletiva a respeito de políticas públicas, visando atingir toda a sociedade ou vários segmentos desta; 2. tratou de ações que visam assessorar ou intervir em problemas coletivos de grupos específicos (geralmente comunidades ou bairros, em especial por meio de intervenções jurídicas ou projetos); 3. tratou da assessoria à organização de pequenos grupos, como acompanhamento a atividades de organização (elaboração e registro de estatutos e assembleias), ou pequenas assessorias por meio

140 de seus representantes, como participação e incentivos para eventos; 4. tratou de denúncias ou acompanhamentos de casos de violação de direitos humanos exemplares, circunscritos no tempo e no espaço.

A chave da separação desses níveis baseia-se num gradiente macro-micro, assim como, de certa forma, coletivo-individual, ou seja, ações que visam atingir a sociedade como um todo, passando por aquelas voltadas para comunidades e grupos, para grupos e associações, até casos de denúncias de violação que podem ter como vítima apenas um indivíduo ${ }^{22}$. Como se poderá constatar, as ações de cada nível não se distribuem equitativamente para cada tema, mas relacionam-se ao tema e tipo de direito a ser defendido. Foram selecionadas 94 matérias publicadas nos boletins

\footnotetext{
${ }^{22}$ No caso do nível 4, incluímos também denúncias e casos circunscritos no tempo e espaço, mesmo que atinjam um coletivo, desde que seja uma denúncia e não faça parte dos grupos assessorados pela FMMA.
} 
da FMMA em 21 boletins, entre 2002 e 2010. Há uma lacuna entre 2006 e 2008, devido à indisponibilidade destes na página eletrônica da FMMA. As notícias foram assim classificadas: 33 (35\%) em controle social; 24 (26\%) em reforma urbana e direito à terra; $17(18 \%)$ em meio ambiente e 20 (21\%) em gênero/mulher.

\section{Controle Social}

O primeiro tema é aquele que possui maior concentração de atividades de nível 1. Esse tema, de definição mais abrangente, apesar da referência bastante difusa, é também altamente recorrente. Ao comentar o nepotismo no Judiciário, assunto em voga à época na Paraíba, a técnica da FMMA Verônica Rodrigues defende o controle social:

Assim, compreender o funcionamento dos órgãos públicos, discutir e acompanhar o orçamento, onde estão previstos os recursos e como serão gastos e a efetiva implementação do dinheiro arrecadado, exigir atendimento dos setores públicos, não pode ser coisa para técnico, mas para todos os cidadãos e cidadãs, que se assim não fazem, perdem força de reivindicação, por não conseguirem exercer o efetivo controle social. Os canais de participação já estão implantados. Precisamos agora efetivar seu funcionamento, através de um processo educativo amplo para o exercício da cidadania relativo a desmistificar o tecnicismo que sempre quer provar que os gestores entendem mais as nossas necessidades que nós mesmos (Rodrigues, 2005, p.2).

A atuação da FMMA está estreitamente ligada ao mundo jurídico, e em boa parte dos casos, isso se traduzirá em ações e advocacy por vias jurídicas, seja impetrando ações, seja defendendo uma ampliação do acesso à justiça, a reforma e controle externo do Judiciário. As ações dessa fundação abrangem a realização de seminários, participação em 
fóruns e conferências, entre os quais os já citados fóruns permanentes Articulação Estadual de Políticas Públicas, Ferurb e Focoej, além das Conferências de Direitos Humanos e Conferências das Cidades - em níveis municipal, estadual e federal -, entre outros eventos.

No que classificamos como nível 2 de ações, há projetos como o "Espaço Legal", financiado pela Brazil Foundation, "destinados à sensibilização, capacitação e estímulo à participação política e jurídica para promover a regularização fundiária de 186 famílias das duas localidades de Forte Velho, em Santa Rita, e Mussumagro, em João Pessoa”. (FFMA, 2004b). Também estimula a participação dos juristas em diversos canais como o processo de orçamento participativo e conselhos municipais.

Em relação à assessoria a pequenos grupos, não houve casos no nível 3.

No nível 4, encontramos o acompanhamento de 142 casos impunes que se arrastam a longo prazo, como o assassinato de Margarida Maria Alves. Há também casos como a cobrança de providências sobre a utilização de ruas como estacionamento privativo ao redor de prédios do Poder Judiciário, caso denunciado ao Focoej.

\section{Reforma Urbana e Direito à Moradia e Terra}

O tema do direito à terra está presente desde a criação da FMMA como CDDH e é uma das suas mais importantes linhas de atuação e intervenção. Embora haja diversidade entre os três temas que enunciamos, entendemos que são temas que se aproximam e podem ser entendidos como desenvolvimentos ao direito à terra. A reforma urbana relaciona-se com o direito à moradia (não é só necessário conquistá-la, é preciso dotar de infraestrutura o novo bairro, o que nem sempre ocorre). O direito à terra associa-se claramente aos dois primeiros temas, pois discute a permanência e sobrevivência de habitantes de áreas rurais há muito instalados nessas terras, 
tematizando de forma semelhante a desigualdade entre ricos e pobres no que tange à propriedade.

Nesses temas, as atividade tem maior ocorrência nos níveis 1 e 2, isto é, tanto na elaboração de políticas e participação em fóruns, como na intervenção para resolução de situações específicas. Esse trecho de artigo de técnica da FMMA expõe sua definição:

Reforma urbana pode parecer algo técnico, incompreensível ou mais um discurso propositalmente elaborado para que a maioria da população não entenda e, assim, não possa acessar o seu direito. Diferentemente disso, reforma urbana diz respeito à vida das pessoas e trata da desigualdade de moradia, saneamento básico, acesso daqueles direitos que todos nós gostaríamos de ter, mas não sabemos onde buscar. [...] Para isso, precisamos ver a cidade como extensão de nossas casas, para podermos desenvolver trabalhos de valorização de nossas ruas, bairros, com sua cultura, mas também para nos envolvermos nas lutas mais coletivas que cobram participação da sociedade nas decisões importantes para a cidade. Precisamos criar espaços públicos de participação e de cobrança (Rodrigues, 2004, p.2).

As atividades de nível 1 são, na sua maioria, a participação no já citado Ferurb. As ações relacionam-se à política habitacional de João Pessoa, alvo de denúncias na gestão de Cícero Lucena (1997-2004), quando da implantação do Programa "É Pra Morar". Via Ferurb, a fundação fez incursões ao Ministério Público, solicitando providências sobre a má-qualidade das habitações as quais, segundo pareceres técnicos, corriam risco de desabamento (FMMA, 2004a). Acompanhou também o desenvolvimento da política habitacional no mandato de Ricardo Coutinho, sucessor de Lucena, assim como dos prefeitos de Bayeux (Jota Júnior) 
e Santa Rita (Marcos Odilon Ribeiro Coutinho). Também militou na campanha pela elaboração/revisão de Planos Diretores em cidades paraibanas, e assessorou municípios nesse sentido.

Em um nível mais interventivo, mas ainda orientado para comunidades, a FMMA procurou contribuir com questões habitacionais e fundiárias. Ainda que sua atuação seja urbana, em várias ocasiões interveio em problemas enfrentados por comunidades em áreas rurais, comuns na região metropolitana de João Pessoa.

Um exemplo é a assessoria e apoio à Associação de Moradores de Forte Velho, distrito de Santa Rita, que a FMMA acompanha desde 2003: naquele ano, o conflito já somava nove anos de disputa judicial (e que perdura até os dias de hoje). As famílias da comunidade ocupavam uma área de 450 hectares e viviam sob ameaça, além de terem sofrido com o envenenamento de lavouras e o incêndio 144 de moradias. A ocupação derivava de situação generalizada em diversas áreas do Nordeste, o "morador de condição”, lavrador que pedia permissão para morar e produzir em determinada grande propriedade; para pagar o aluguel da terra, deveria realizar o "cambão" (dias de trabalho na lavoura do proprietário), relação de conotação servil a que os moradores deveriam se sujeitar. Com o avanço da indústria sucroalcooleira e a morte dos antigos proprietários com os quais o acordo havia sido feito, muitos moradores de condição foram expulsos e, quando se recusavam a sair, eram ameaçados e agredidos (Mitidiero, 2008). A luta pela eliminação do cambão foi um dos principais motivos para organização das ligas camponesas na Paraíba ${ }^{23}$.

\footnotetext{
${ }^{23}$ As ligas camponesas da Paraíba reivindicavam principalmente o direito de plantar nas terras em que moravam, e que o pagamento do trabalho da lavoura do proprietário fosse feito em dinheiro (os moradores, por sua vez, pagariam também o aluguel da terra em dinheiro), atenuando a dependência do proprietário da terra. Em Pernambuco, elas reivindicavam principalmente a extensão
} 
Ainda na década de 1980, moradores da comunidade de Forte Velho pagavam cambão ao proprietário das terras. Com a morte deste, os herdeiros vendiam as terras, inclusive as com moradores, que ficaram a mercê dos novos proprietários, enfrentando ameaças, redução do terreno (possibilitando apenas a moradia, e não mais a cultura agrícola de subsistência), o que motivou a organização dos moradores para a garantia de permanência ${ }^{24}$. Além do caso de Forte Velho, a FMMA move ação de regularização em área de usucapião urbano, no bairro Mussumagro, João Pessoa.

Ao lado dessas intervenções, a FMMA procura, em um terceiro nível, acompanhar a formação e formalização de associações de moradores para que possam continuar reivindicando melhorias para as comunidades. Uma via importante de intervenção nesse tema passa pela organização comunitária:

A falta de regularização fundiária também piora os outros problemas enfrentados pela população, como a inexistência de rede coletora de esgoto, escola ou creche e as dificuldades de funcionamento do Programa de Saúde da Família. [...] Verônica [técnica da FMMA à época] explica que o projeto prevê o envolvimento da comunidade em todo o processo da regularização, através de oficinas e reuniões realizadas por técnicos da Fundação. "Esta é uma das partes mais importantes do trabalho, fazer com que o processo seja bastante participativo", garante (FMMA, 2008b, p.4).

Nesse trecho, a noção de "controle social" se traduz em termos mais técnicos na aposta no fortalecimento da

das leis trabalhistas aos trabalhadores das usinas. Souza (1996) relata a relação autoritária e violenta dos principais latifundiários da região da Várzea do Paraíba na época das ligas.

${ }^{24}$ Mitidiero (2008) narra com pormenores os conflitos da Fazenda Tambauzinho, comunidade vizinha a Forte Velho. 
organização "do povo", da sua participação organizada nos canais institucionais, por meio dos quais poderá fazer valer seus direitos. No caso da reforma urbana, assim como direito à moradia e terra, temos o direito coletivo por excelência, sempre reivindicado por um grupo.

\section{Meio Ambiente}

Apesar de ter sido a que teve menor número de notícias na classificação por temas, a defesa do meio ambiente é cada vez mais recorrente nas ações da FMMA. Isso se deve, em grande medida, pela eleição do meio ambiente como tema principal de atuação da rede de juristas. Classificamos em nível 1 as ações que abrangessem os quatro núcleos de juristas e sua atuação nas políticas públicas, como incursões feitas à Superintendência de Administração do Meio Ambiente (Sudema) ${ }^{25}$ e ao Instituto Nacional de Meio Ambiente e Recursos Naturais Renováveis (Ibama).

146 Um dos casos que se tornam objeto de intervenção da Rede de Juristas Populares é a salinização das cacimbas ${ }^{26}$, denunciada pela Associação de Moradores de Forte Velho como resultado da carcinicultura, a criação de camarões em viveiros. Realizou-se ato público, no qual representantes de várias instituições estiveram presentes, desde a Sudema e o Ibama, representantes da FMMA e da ONG Associação Paraibana dos Amigos da Natureza (Apan).

Nos níveis 2 e 3, temos a maioria dos esforços envidados para a preservação da Mata do Xem-xem, localizada em Bayeux. Desde audiências públicas (nível 1), composição do conselho gestor da mata e mobilização da população local promovidas pelos juristas e assessorada pela FMMA (nível 2), até plantio de mudas de espécies nativas em cla-

\footnotetext{
${ }^{25}$ Órgão ambiental do governo da Paraíba.

${ }^{26}$ As cacimbas são poços, feitos por meio de escavação, onde a água do solo se acumula. Muito comum no Nordeste, era a fonte de água potável da população de Forte Velho, que atualmente possui água encanada.
} 
reiras identificadas previamente pelos juristas, piqueniques ecológicos e caminhadas de limpeza da mata (nível 3). Em Tibiri (Santa Rita), são promovidas caminhadas denominadas "Via Sacra do Meio Ambiente", que reúne alunos de escolas públicas e privadas (nível 2). Essa "Via Sacra" é parte importante da também anual "Semana do Meio Ambiente", promovida pelos juristas da localidade, que realizam oficinas nas escolas (nível 3). Já pela sua denominação, pode-se notar a marca deixada por religiosos da Igreja Católica progressista, frequentemente citados por juristas quando relatam mobilizações realizadas em seus bairros/comunidades. Em nível 4, encontramos apenas uma denúncia contra "a impunidade relacionada ao rompimento da Barragem de Camará" em Alagoa Grande, na qual seu rompimento havia levado a cinco mortes e milhares de desabrigados.

A importância atribuída ao tema meio ambiente e sua escolha como linha principal de atuação da Rede de Juristas Populares não deixam de refletir diversos aspectos valorativos em circulação ali. Tanto em sentido macrocultural, como a valorização da natureza, da terra e da imagem do sertanejo/nativo, como, da perspectiva da FMMA, no valor político dos direitos coletivos. Estes, além de estarem associados com o direito à terra/moradia, e, portanto, com o direito à cidade de uma forma mais ampla, associam-se também à qualidade de vida urbana, isto é, à coleta de lixo, ao saneamento básico e ao abastecimento de água tratada - serviços que ainda eram prestados, nas regiões periféricas da Grande João Pessoa, com muita deficiência. Esses problemas foram aglutinados sob o tema do meio ambiente, aliados à defesa da natureza de forma, digamos, mais direta, como o combate ao desmatamento. A temática de defesa do meio ambiente também encontra, na região metropolitana de João Pessoa, um tecido urbano permeado de matas e modos de vida próximos aos característicos do rural, conforme enfatiza Maia (2000). 


\section{Gênero/Mulher}

Gênero como tema, na classificação aqui proposta, irá incluir toda e qualquer referência à igualdade/desigualdade entre os sexos, a problematização de questões ligadas à condição feminina (violência doméstica, dupla jornada, participação na política etc.) e quaisquer referências à discussão sobre sexualidade. Apesar de ser um tema minoritário, a referência a gênero é bastante frequente. Ocorre que, diferentemente dos demais temas, gênero não se traduz, de forma significativa, em ações da FMMA.

Assim temos, em um primeiro nível, apenas a participação da FMMA na Rede de Mulheres da Paraíba por meio da atuação de uma das técnicas (notadamente militante feminista). Esta se traduz em ação pontual, no início da publicação do seu boletim. Vez por outra, são noticiados eventos relativos à Rede, como a comemoração do Dia da Mulher Latino-Americana, ou a participação na Conferência Nacional de

148 Mulheres, porém, sem uma participação direta da FMMA.

Não encontramos nenhuma ação que possa ser classificada como de nível 2. Já no terceiro nível, podemos encontrar notícias sobre as atividades desenvolvidas pelo Flor Mulher ${ }^{27}$, grupo próximo à FMMA. Desde o início, essa organização foi acompanhada pela FMMA na sua constituição, principais atividades, até a conquista da sede própria, uma casa "doada por uma missionária que acompanha o grupo há vários anos” (FMMA, 2005).

Num quarto nível, que inclui denúncias e acompanhamento de casos de violação, o volume de informação é o maior entre todos quatro níveis, com pelo menos três casos importantes, de numerosas inserções no informativo. O primeiro deles foi um caso de acusação de atos libidinosos con-

\footnotetext{
${ }^{27}$ Flor Mulher é uma organização que surge a partir de formações de grupos de mulheres para discussão de problemas de saúde mental, que foram iniciados por missionárias da ordem católica de linha progressista Maryknoll (originária dos EUA).
} 
tra uma menor praticados pelo juiz José Edvaldo Albuquerque de Lima no exercício de suas funções, já que ele pertencia ao Juizado da Infância e Juventude da cidade de Bayeux. O Conselho Tutelar da cidade o teria denunciado e sofrido ameaças. O caso foi classificado no tema de gênero por se tratar de uma violência contra uma adolescente, embora o caso tenha sido tratado muito mais do ponto de vista do abuso de autoridade e da ameaça aos membros do conselho tutelar de Bayeux.

Os dois casos restantes são violações contra mulheres, que ficaram conhecidos como Caso Márcia Barbosa e Caso Rosângela. A estudante Márcia Barbosa foi assassinada em 1998, e todos os indícios apontavam para o então deputado estadual paraibano Aércio Pereira de Lima. A morte causou comoção e mobilizou diversas entidades de direitos humanos do estado e do Ministério Público, o que ocasionou mudanças nas regras de imunidade parlamentar em crimes comuns (Emenda Constitucional n. 135, de 2001). Além da FMMA, se envolveram no caso a Gabinete de Assessoria Jurídica às Organizações Populares (Gajop), de Recife e Centre for Justice and International Law (Cejil), organização internacional com escritório no Rio de Janeiro. O caso foi considerado emblemático e estava sendo acompanhado pela Corte Interamericana de Direitos Humanos.

E, por fim, o terceiro caso noticiado foi o de Rosângela Silva Santana, de 38 anos, ocorrido em 2006. Rosângela se separara do marido, o cabo da PM Júlio Galdino Santana Filho, em razão de constantes agressões. Porém, depois de dois anos de separação, resolveu dar nova chance ao relacionamento. Após alguns meses, o marido voltou a agredi-la, o que culminou em um episódio extremamente violento, em que Rosângela foi amarrada, ameaçada com arma de fogo e teve suas roupas rasgadas. Rosângela foi capturada nua, tentando fugir. Apesar de ter sido vítima da violência do ex-marido, ela foi presa sob acusação de tentativa de homicí- 
dio. Na delegacia, para onde foi levada por colegas do ex-marido, Rosângela permaneceu nua durante várias horas. Ficou três dias presa, até a concessão de habeas corpus. A defesa de Rosângela foi acompanhada pela FMMA, entre outras organizações de mulheres.

Muitas notícias classificadas como "gênero" não puderam, no entanto, ser incluídas em nenhum dos quatro níveis. São matérias meramente informativas, no sentido de que não noticiavam atividades da FMMA, mas de outras organizações (como atividades da União Brasileira de Mulheres ou da Rede de Mulheres da Paraíba), ou mesmo, da realização de encontros e conferências (por exemplo, a Conferência Nacional de Políticas para as Mulheres). Também havia quase nenhuma referência à sexualidade, apenas notícias de formações no assunto ministradas por outras organizações.

Assim, no que tange às questões de gênero no interior do frame da FMMA, pode-se afirmar que estas se consubs150 tanciam na referência aos problemas das mulheres, em especial, às pobres. Há dificuldade em elaborar as questões de gênero, originárias dos movimentos feministas, em termos coletivos. A temática, apesar de amplamente referenciada em notícias dos boletins, não consegue ser incorporada facilmente ao frame da FMMA. De perspectiva coletivista e que se centra em questões como desigualdade e pobreza, este encontra dificuldade em conectar-se ao frame feminista. Ainda que haja pontos de contato, a temática de gênero toma a pobreza e a desigualdade como agravantes de uma condição que, não sendo de classe nem econômica, é elaborada em termos de diferenças sexuais. Desse modo, embora não seja um tema amplamente trabalhado em termos de sua atuação, serve para sublinhar, por contraste, os principais aspectos do seu frame, alinhado com um master frame de direitos humanos. 
$\mathrm{O}$ artigo procurou, a partir da análise sobre a formulação do frame da FMMA, uma organização de longo percurso na defesa de direitos humanos no estado da Paraíba, iluminar pontos de formação do master frame de direitos humanos no Brasil. Desde sua criação como CDDH, na década de 1970, a organização passou por diversas fases. Nasce como defensora dos direitos dos camponeses em conflitos fundiários, com o intuito de promover assistência jurídica, numa via legalista de luta pela terra, durante a ditadura militar.

Com origem na Igreja Católica, a FMMA não rompe com as redes de relações estabelecidas, pois tem seus principais projetos financiados por agências católicas internacionais, alinhando-se às suas concepções de assistência ao "povo", que se superpõe ao de "pobres". Muitas vezes, ao se referir a essas camadas, utiliza uma concepção homogeneizante dos "pobres", objetos da injustiça dos "ricos/poderosos". Ainda que esteja alinhada às orientações de suas financiadoras, deve-se observar que, para além disso, financiadores e financiados compartilham objetivos e entendimentos comuns sobre o que significa defender os direitos humanos, e esse alinhamento se deve, certamente, ao compartilhamento de valores religiosos de mesma origem, ou seja, a cristã. Examinar a questão sob essa perspectiva permite compreender melhor essas relações, em vez de tomar como dado que as organizações financiadas distorcem seus objetivos em busca de financiamentos, assim como também é simplista afirmar que as agências impõem uma agenda.

Por outro lado, o master frame também sofre, internamente, processos de framing amplamente influenciados pela Igreja Católica: sabe-se que sob a ditadura, os segmentos progressistas dessa igreja foram apoios importantes da resistência ao regime. $\mathrm{O}$ antecessor da FMMA corresponde a um daqueles equipamentos criados pela Igreja Católica para responder ao vácuo do Estado e ao seu fechamento às demandas da socie- 
dade. Esses organismos até hoje permanecem na ativa, adaptados aos novos tempos de democracia.

Por fim, a atuação da FMMA mostra ainda a perspectiva fortemente coletivista, calcada no auxílio a "comunidades", regiões de bairros pobres que possuem laços primários, familiares e de vizinhança fortes. O auxílio ao "povo pobre" se dá por meio da intermediação entre essas comunidades e os espaços de mediação de políticas públicas, "dando voz" às suas demandas. Essa perspectiva, porém, enxerga certos problemas como "mais coletivos" do que outros: a luta por terra ou moradia, que garante o estabelecimento da família, e por extensão, da comunidade, é privilegiada nesse frame. Porém, outras questões, como as relacionadas a gênero, entram com dificuldade nessa elaboração, pois, por vezes, supõem romper com um ideário de preservação da família tradicional, base dos laços comunitários. Isto é, com base na análise apresentada, podemos lançar a hipótese de obstácu152 los cognitivos (verdadeiras “cegueiras") a certas questões. Assim, um master frame amplo e genérico de direitos humanos ganha colorações próprias em determinados contextos, em razão não somente de interesses das organizações, mas de ressonância de valores entre aqueles que se propõem a defender certas causas. Porém, pode-se afirmar como uma característica central do master frame de direitos humanos no Brasil, o privilégio da defesa dos direitos coletivos.

\section{Arlene Martinez Ricoldi}

é doutora em sociologia pela USP e pesquisadora da Fundação Carlos Chagas.

\section{Referências bibliográficas}

ALBUQUERQUE, D. M. 2009. A invenção do nordeste e outras artes. São Paulo: Cortez.

BONELLI, M. G. 2005. "Ideologias do profissionalismo em disputa na magistratura paulista”. Sociologias, ano 7, n.13, p.110-35.

CLADEM. 1991. Capacitación legal a mujeres. Lima: Cladem. 
DOIMO, A. M. 1995. A vez e a voz do popular: movimentos sociais e participação política no Brasil pós-70. Rio de Janeiro: Relume-Dumará; Anpocs.

FMMA. 2004a. "Relator nacional visita condomínios populares". Falando DHireito, ano 3, n.5, p.10.

. 2004b. "Fundação conquista nova parceria: projeto da FDDHMMA é selecionado pela Brazil Foundation”. Falando DHireito, ano 1, n.2, p.3. 2005. "Flor mulher ganha casa e amplia atendimento em $80 \%$ ". Falando DHireito, ano 2, n.6, p.5.

2006. "Fundação abre inscrições para Curso de Formação de Juristas Populares". Disponível em <http://www.fundacaomargaridaalves. org.br/2006/02/01/fundacao-abre-inscricoes-para-curso-de-formacao-de-juristas-populares/>. Acesso em 21.09.2010.

2008a. "Estatuto da Fundação de Defesa dos Direitos Humanos Margarida Maria Alves”. Disponível em <http://www.fundacaomargaridaalves.org.br/wp-content/uploads/2010/08/Estatuto-Vigente-da-Funda\%C3\%A7\% C3\%A3o-Margarida-Maria-Alves.pdf $>$. Acesso em 24/05/2012.

2008b. "Ministério aprova contas de 2003 a 2006 da Fundação e elogia gestão”. Falando DHireito, ano 8, n.16, p.1.

2011. "Rede de juristas populares avaliam atuação em 2010 e prepara atividades de 2011". Falando DHireito, ano 9, n.24, p. 5.

GOFFMAN, E. 1974. Frame analysis: an essay on the organization of experience. London: Penguin.

MAGALHÃES, C. M. 2002. "Cidadania e direitos humanos". Boletim Intergrupos, ano 1, n.2, p.1.

2005. "Consciência ecológica e cidadania". Falando DHireito, ano 2, n.5, p.2.

MAIA, D. S. 2000. Tempos lentos da cidade: permanências e transformações dos costumes rurais da cidade de João Pessoa-PB. Tese de doutorado em geografia humana. São Paulo: FFLCH-USP.

MITIDIERO JR, M. A. 2008. A ação territorial de uma igreja radical: teologia da libertação, luta pela terra e a atuação da comissão pastoral da terra no estado da Paraíba. Tese de doutorado em geografia humana. São Paulo: FFLCH-USP.

OLIVER, P.; JOHNSTON, H. 2000. "What a good idea! Ideologies and frames in social movement research". Mobilization, v.4, n.1, p.37-54.

PESSOA, M. 2005. "Outorga onerosa: instrumento de justiça social?”. Falando DHireito, ano 2, n.6, p.2.

PORTO, M. P. 2000. "Enquadramentos de mídia e política”. Texto apresentado no XXVI Encontro da Anpocs. Caxambu. 
REIS, R. A. 2011. "América Latina e os direitos humanos". Contemporânea, n.2, p.101-15.

RICOLDI, A. M. 2011. Paraíba mulher macho: gênero, cultura e política na educação jurídica popular em João Pessoa-PB. Tese de doutorado em sociologia. São Paulo: FFLCH-USP.

RODRIGUES, V. 2004. "A reforma urbana depende de você". Falando DHireito, ano $1, \mathrm{n} .2, \mathrm{p} .2$.

ROJAS, F. 1988. "A comparison of change-oriented legal services in Latin America with legal services in North America and Europe". International Journal of the Sociology of Law, n.16, v.2, p.203-56.

SANTOS, B. S. 1997. "Uma concepção multicultural de direitos humanos". Lua Nova, n.39, p.105-201.

SCHULER, M.; KADIRGAMAR-RAJASINGHAM, S. (orgs.). 1992. Legal literacy: a tool for women's empowerment. New York: Unifem.

SNOW, D. A.; BENFORD, R. D. 1992. "Master frames and cycles of protest". In: MORRIS, A.; MUELLER, C. M. (orgs.). Frontiers in social movement theory. New Haven; London: Yale University Press, p. 133-55.

2000. "Framing processes and social movements: an overview and assessment”. Annual Review of Sociology, n. 26, p. 611-639. et al. 1986. "Frame alignment processes, micromobilization, and movement participation”. American Sociological Review, v.51, n.4, p.464-81.

SOUZA, F. A. L. 1996. Nordeste: o Vietnã que não houve - ligas camponesas e o golpe de 1964. Londrina: Eduel.

STEINBERG, M. 1998. "Tilting the frame: considerations on collective action framing from a discursive turn”. Theory and Society, n.27, p.845-72.

YPIRANGA NETO, M. 2009. "Direitos humanos: caminho para sociedade livre, justa e solidária”. Falando DHireito, ano 6, n.19, p.2. 


\section{TEMAS EM DIREITOS HUMANOS DE UMA ORGANIZAÇÃO DA PARAÍBA E 0 MASTER FRAME DE DIREITOS HUMANOS}

\section{ARLENE MARTINEZ RICOLDI}

Resumo: Utilizando-se do conceito de frames, o artigo procura delimitar um master frame de direitos humanos entre organizações não governamentais brasileiras que orienta ações e ativismo destas. Analisa-se particularmente a atuação da Fundação Margarida Maria Alves, sediada em João Pessoa, na Paraíba, utilizando principalmente os boletins informativos editados pela organização. O exame de sua trajetória e frame ilumina aspectos da construção de um master frame de direitos humanos no Brasil.

Palavras-chave: Direitos humanos; Fundação Maria Margarida Alves; Frame; Master frame.

\section{HUMAN RIGHTS ISSUES OF AN ORGANIZATION IN PARAÍBA AND THE HUMAN RIGHTS'S MASTER FRAME}

Abstract: Using the frames approach, the paper attempts to outline a human rights master frame in force among nongovernmental organizations in Brazil that guides its actions and activism. This article examines in particular the work of the Margarida Maria Alves Foundation, based in João Pessoa, Paraíba, using mainly the newsletters published by the organization. The examination of its trajectory and organizational frame illuminates aspects concerning building a human rights master frame in Brazil. 
Keywords: Human Rights; Maria Margarida Alves Foudation; frame; master frame. 